\title{
SIGATOKA NEGRA DA BANANEIRA NO ESTADO DO PARÁ
}

\section{DINALDO R. TRINDADE, LUIZ S. POLTRONIERI \& ANTÔNIO JOSÉ E. A. MENEZES}

Embrapa Amazônia Oriental, Cx. Postal 48, CEP 66095-100, Belém, PA, e-mail: dinaldo@cpatu.embrapa.br

(Aceito para publicação em 09/04/2002)

Autor para correspondência: Dinaldo Rodrigues Trindade

\section{ABSTRACT \\ Black sigatoka of banana in the State of Pará}

The most serious disease reported in banana (Musa sp.) caused by Mycosphaerella fijiensis has been occurring in the State of Pará, Brazil, since 2000 .
O estado do Pará é um dos principais produtores de banana (Musa sp.) no Brasil e sua produção é utilizada tanto para consumo "in natura", em razão de a banana constituir um componente básico da alimentação de sua população, como para comercialização em outros centros do país. A partir do ano 2000, com a ocorrência da doença conhecida como sigatoka negra, causada pelo fungo Mycosphaerella fijiensis Morelet, o estado do Pará está sendo impedido de exportar sua produção de banana. A sigatoka negra é uma doença quarentenária do tipo A2 e por essa razão não pode ser transportada para outras regiões onde ainda não ocorre. A doença foi detectada na parte norte do Estado, em algumas touceiras de bananeira, nos municípios de Almeirim e Porto de Moz (Figura 1). A confirmação da doença foi feita através da visita de uma equipe de especialistas no local, constituída de pesquisadores da ENCAPER, Ministério da Agricultura Pecuária e Abastecimento e Embrapa Amazônia Oriental. Por ocasião da análise do quadro sintomatológico, a equipe observou a presença de estrias negras ao longo das nervuras secundárias tomando todo o limbo foliar, necrose das folhas e seca total da planta e concluiu que os sintomas eram característicos causados pelo fungo $M$. fijiensis, agente da sigatoka negra, conforme citado na literatura (R.H.Stover, Plant Disease, 64:750-756. 1980). A análise microscópica foi realizada pelo Dr. Rogério Hanada, pesquisador do Instituto de Pesquisa da Amazônia- INPA, que observou nas amostras as características citadas na literatura para o fungo M. fijiensis, que são: conidióforos simples emergindo de estromata e conidios longos e curvados com 50-120 $\mu \mathrm{m}$, largura de 3.5-5.0 $\mu \mathrm{m}$ com até seis septos e um hilo basal que é uma das características marcantes desse fungo. É provável que a doença tenha sido introduzida através do estado do
Amapá por meio de material trazido das Guianas onde já ocorre há algum tempo. Nessa região do estado do Pará onde foi detectada a doença, não existem plantios comerciais, e como medidas para conter a doença foram distribuídas nos dois municípios mudas de bananeira resistentes a sigatoka negra, das variedades Thap Maeo, Caipira, FHIA 18, FHIA 20 e FHIA 21. Para contornar o problema de comercialização de banana para fora do Estado, está sendo pleiteado junto ao Ministério da Agricultura, Pecuária e Abastecimento que a região sul do Pará seja considerada área livre da sigatoka negra, em razão de que nessa região é onde se localizam os grandes plantios comerciais e está separada da região de ocorrência da doença por uma grande barreira natural que certamente impedirá uma disseminação rápida da doença.

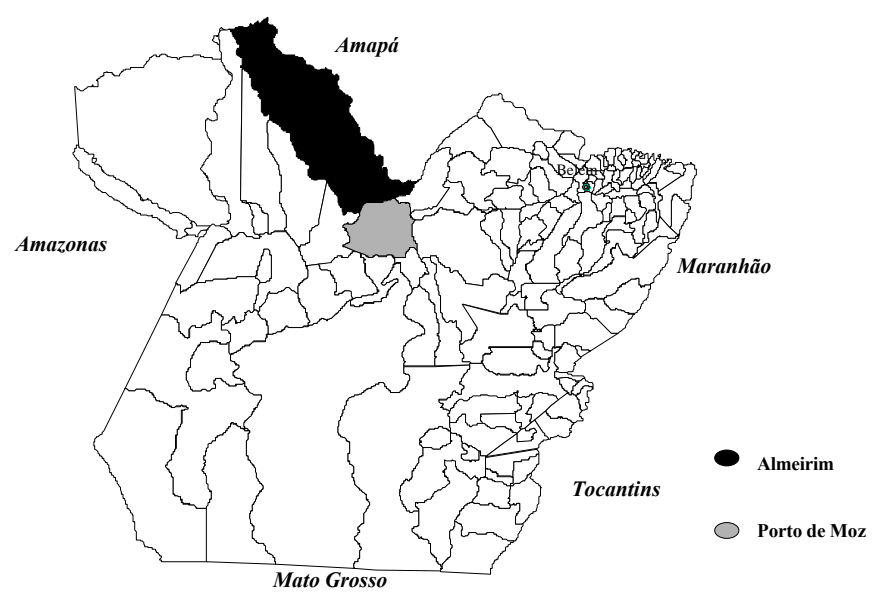

FIG. 1 - Municípios do estado do Pará (Almeirim e Porto de Moz) com Sigatoka Negra 